\title{
The definition of immigrant status matters: impact of nationality, country of origin, and length of stay in host country on mortality estimates
}

\author{
Luis Andrés Gimeno-Feliu ${ }^{1,2,3,4^{*}}$ (D), Amaia Calderón-Larrañaga ${ }^{1,3,5}$, Esperanza Díaz ${ }^{6,7}$, Clara Laguna-Berna ${ }^{1,3}$,
} Beatriz Poblador-Plou ${ }^{1,3}$, Carlos Coscollar-Santaliestra ${ }^{1,2,4}$ and Alexandra Prados-Torres ${ }^{1,3}$

\begin{abstract}
Background: Mortality is a robust indicator of health and offers valuable insight into the health of immigrants. However, mortality estimates can vary significantly depending on the manner in which immigrant status is defined. Here, we assess the impact of nationality, country of origin, and length of stay in the host country on mortality estimates in an immigrant population in Aragón, Spain.

Methods: Cross-sectional retrospective study of all adult subjects from the EpiChron Cohort in 2011 ( $n=1,102,544)$, of whom 146,100 were foreign-born (i.e., according to place of birth) and 127,213 were non-nationals (i.e., according to nationality). Directly standardized death proportions between years 2012-2015 were calculated, taking into account the age distribution of the European population in 2013. Binary logistic regression was used to compare the four-year probability of death.

Results: The age- and sex-standardized number of deaths per 1000 subjects were $45.1(95 \% \mathrm{Cl} 44.7-45.2)$ for the Spanish-born population, $29.3(95 \% \mathrm{Cl} 26.7-32.1)$ for the foreign-born population, and $18.4(95 \% \mathrm{Cl} 15.6-21.6)$ for non-Spanish nationals. Compared with the Spanish-born population, the age- and sex-adjusted likelihood of dying was equally reduced in the foreign-born and non-national populations (OR $0.6 ; 95 \% \mathrm{Cl} 0.5-0.7$ ) when the length of stay was less than 10 years. No significant differences in mortality estimates were detected when the length of stay was over 10 years.

Conclusions: Mortality estimates in immigrant populations were lower than those of the native Spanish population, regardless of the criteria applied. However, the proportion of deaths was lower when immigrant status was defined using nationality instead of country of birth. Age- and sex-standardized death proportions tended to increase with increased length of stay in the host country.
\end{abstract}

Keywords: Emigration and immigration, Mortality, Population groups, Health inequalities, International health, Spain

\footnotetext{
* Correspondence: lugifel@gmail.com

${ }^{1}$ EpiChron Research Group on Chronic Diseases, Aragón Health Sciences

Institute (IACS), IIS Aragón, Miguel Servet University Hospital, Zaragoza, Spain

${ }^{2}$ Aragón Healthcare Service, San Pablo Health Centre, Zaragoza, Spain

Full list of author information is available at the end of the article
}

(c) The Author(s). 2019 Open Access This article is distributed under the terms of the Creative Commons Attribution 4.0 International License (http://creativecommons.org/licenses/by/4.0/), which permits unrestricted use, distribution, and reproduction in any medium, provided you give appropriate credit to the original author(s) and the source, provide a link to the Creative Commons license, and indicate if changes were made. The Creative Commons Public Domain Dedication waiver (http://creativecommons.org/publicdomain/zero/1.0/) applies to the data made available in this article, unless otherwise stated. 


\section{Background}

Migration is a global phenomenon with important implications for health systems [1]. According to the 2018 United Nations Migration Report, the number of migrants worldwide reached 244 million in 2015 and it is expected to continue to grow [2]. In fact, recent years have seen growing interest in the health status and health determinants of immigrant populations [3-6], the impact of their care on health systems $[7,8]$, and the design of strategies to improve their health [9].

The International Organization for Migration (IOM) defines an international immigrant as a non-national person who is moving into a country for the purpose of settlement [10]. Other authors use more general definitions, e.g., a person who has established a (semi-) permanent new residence in a "place" other than that in which they habitually lived [11]. In this definition, "place" is generally understood as a locality, district, or higher administrative area. Often, the terms immigrant and foreigner or foreign-born are used interchangeably.

However, the different ways of classifying immigrant status can lead to disparate outcomes in studies conducted on these populations. It is therefore important to take into account the definition used when interpreting and comparing the results of different studies. Two main definitions are found in the literature:

- Foreign-born [11]: a person born in a country other than their current country of residence. This defines an invariable status but excludes second and third generations of immigrants since it is independent of the migratory status of their parents/grandparents. This is the most commonly used definition in the literature.

- Foreigner or non-national [10]: a person belonging to, or owing an allegiance to, another state. This status can vary over time and as a function of the legal requirements of each state, which often depend on historical links between countries.

In 1999, Loue et al. [12] argued for the need to clearly define these terms in research studies. Regardless of the concept used, we have not found any previous studies that compare the impact on health outcomes of the use of different definitions.

Spain has one of the largest immigrant populations in absolute numbers in Europe. At the time this study was conducted (i.e., 2011), around 6 million immigrants, defined as those born in another country, were living in Spain, accounting for $13 \%$ of the total population, and the National Health Service offered universal coverage regardless of immigrants' legal status [13]. In Aragón, a region in north-eastern Spain with 1.3 million inhabitants, immigrants represented approximately $13 \%$ of the total population in 2010, a proportion equal to that of the entire country.

As opposed to the principle of place of birth, Spanish nationality is based on the principle of jus sanguinis. Therefore, people who are born in another country but have Spanish parents or mixed-nationality parents with at least one of them born in Spain would also have a Spanish nationality.

This study aims to explore the impact of different definitions of immigrant status on health outcome estimations. We used data from Aragón collected as part of the Epichron Cohort [14], taking mortality as the health indicator. In this cohort, both place of birth and nationality are registered. In addition, we also assessed the influence of length of stay in the host country, since the health of immigrants tends to worsen with increased time spent in the host country [5, 15-17].

\section{Methods}

The EpiChron Cohort [14] gathers individual-level clinical and administrative data from primary, secondary and tertiary care health records and the health insurance database for almost all residents of Aragón. In this study, the following variables were included for individuals 14 years or older in 2011: age, sex, nationality, country of birth, and duration of residence in Aragon. National-level mortality data for years 2012-2015 was linked at the individual level.

Four-year death proportions were directly standardized taking into account the age distribution of the European population in 2013. Binary logistic regression was used to compare the four-year probability of death among individuals 1 ) of a foreign nationality (i.e., non-nationals), and/or 2) born outside of Spain (i.e., foreign-born), with respect to Spanish nationals born in Spain, after adjusting for age (as a continuous variable) and sex. Analyses were stratified by length of stay, applying previously used cut-offs: < 5 years, 5-10 years, > 10 years $[15,18]$. The term "immigrant" was used generically to describe individuals with a foreign nationality and/or born outside of Spain. These two groups were further sub-classified according to geographic location (Africa, Asia, Eastern Europe, Latin America, and Western Europe \& North America).

Statistical analyses were performed using STATA (version 12; StataCorp, College Station, TX, USA). The study was approved by the Ethics Committee for Clinical Investigation of Aragón.

\section{Results}

The population studied consisted of $1,102,544$ people 14 years or older. The main sociodemographic data and number of deaths over the four years of follow-up, stratified according to nationality and place of birth, are 
shown in Table 1. A total of 56,918 deaths were recorded, corresponding to $5.16 \%$ of the population studied. Of these, 428 deaths corresponded to non-nationals who were born outside Spain, while 376 corresponded to Spanish nationals who were born outside Spain.

Figure 1 shows the proportion of deaths between years 2012-2015 according to place of birth and nationality, standardized for age and sex. Differences were non-existent or minimal for individuals of European, North American and Asian origin, but significant for other geographical areas, with higher mortality estimates observed when immigrant status was based on place of birth versus nationality.

Figure 2 shows the proportion of deaths between years 2012-2015 by place of birth and according to nationality. Spanish nationals born abroad had a percentage similar to that of those born in Spain, but much higher than that of non-Spanish nationals born abroad, especially among those born in Africa and Latin America.

Figure 3 shows the four-year probability of death in the foreign-born versus Spanish-born population (the comparison group is depicted using the dotted vertical line) stratified by length of stay. For the foreign-born population, regardless of the place of birth, the probability of dying during the first five years of stay in Spain was lower than that of the Spanish-born population, but this probability increased significantly when the stay exceeded five years, reaching levels comparable to those of the Spanish-born population.

Last, Fig. 4 shows the four-year probability of death according to the definition of immigrant status (place of birth versus nationality) with respect to individuals born in Spain, stratified by length of stay. Length of stay appears to be the main determinant of the risk of mortality, since the probability of dying increases with length of stay to eventually reach levels comparable to those of the Spanish-born population (i.e., > 10 years).

\section{Discussion}

Our study reveals three important findings. First, defining immigrant status based on nationality versus place of birth results in different estimations of mortality. Second, mortality estimates of the immigrant population in Spain are lower than those of the native population, particularly on arrival, regardless of the definition used. Last, mortality increases with the length of stay, reaching a level comparable to that of the native population after 10 years.

\section{Practical implications of the definition of immigrant status}

Our findings show that the definition of immigrant status (nationality versus place of birth) can lead to significant differences in mortality estimates. While place of birth is the criterion most frequently used [15, 19-24], immigrant status has been defined based on nationality in studies conducted in Germany [25, 26], France [27], Italy [28], Denmark [29], and Greece [30]. Several studies performed in the USA [31-34] have used the concept of ethnicity, which to date is less common in European studies. Finally, some researchers also take into account the immigration status of parents [16, 18, 35-37].

As our results indicate, the group for which the greatest disparities are observed consists of individuals whose nationality corresponds to their host country but who were born elsewhere. While multiple factors can contribute to this discordance, the following two scenarios are the most important:

1. Children born abroad with Spanish parents living abroad or mixed-nationality parents with at least one of them born in Spain. These individuals are usually not considered immigrants despite being born outside Spain, and would constitute "false positives" if considered as such.

2. Immigrants who acquire the Spanish nationality by naturalization. Failing to consider these individuals as immigrants could result in the introduction of "false negatives" into research studies. Naturalization policies are very diverse and influenced by historical, geographical, legal, and/or social factors. For example, while a non-national must, in general, reside in Spain for at least 10 years before applying for citizenship, those of Ibero-American, Andorran, Philippine, Equatorial Guinean, Portuguese, or Sephardic origin can apply after only two years.

As shown in Fig. 4, the lower death proportion observed for non-Spanish nationals born outside of Spain compared with Spanish nationals born outside of Spain appears to be due, to a large extent, to the longer duration of stay in the host country in the latter group. We therefore consider it essential that research studies take into account information relating to length of stay, in addition to nationality and place of birth, in order to avoid misinterpretation of results [12].

\section{Comparison of mortality estimates in native versus immigrant populations}

Our results showing lower mortality in the immigrant population are in line with those of previous studies conducted in Europe [3], Norway [16, 35], Belgium [18], Spain [22], Italy [28], England [23], Canada [15, 19, 20], USA [31, 33, 34], France [24], and Denmark [29], although some studies, including one conducted in Greece [30], have reported higher mortality rates in immigrant populations. 
Table 1 Sociodemographic data (2011) and number of deaths (2012-2015) in the study population

\begin{tabular}{|c|c|c|c|c|}
\hline & $\begin{array}{l}\text { Spanish nationals } \\
\text { born in Spain }\end{array}$ & $\begin{array}{l}\text { Spanish nationals } \\
\text { born abroad }\end{array}$ & $\begin{array}{l}\text { Non-Spanish nationals } \\
\text { born abroad }\end{array}$ & Total \\
\hline n (\%) & $956,444(86.75)$ & $18,387(1.67)$ & $127,713(11.58)$ & $1,102,544$ \\
\hline Sex (women), n (\%) & $491,117(51.35)$ & $9849(53.57)$ & $58,526(45.83)$ & $559,492(50.75)$ \\
\hline \multicolumn{5}{|l|}{ Age (years), n (\%) } \\
\hline $15-44$ & $395,767(41.38)$ & $9888(53.78)$ & $100,160(78.43)$ & $505,815(45.88)$ \\
\hline $45-64$ & $298,854(31.25)$ & $6775(36.85)$ & $25,327(19.83)$ & $330,956(30.02)$ \\
\hline $65+$ & $261,823(27.37)$ & $1724(9.38)$ & $2226(1.74)$ & $265,773(24.11)$ \\
\hline Age (years), mean (SD) & $50.9(19.9)$ & $43.7(15.4)$ & $36.4(11.5)$ & $49.1(19.6)$ \\
\hline \multicolumn{5}{|l|}{ Nationality, n (\%) } \\
\hline Spain & $956,444(100.0)$ & $18,387(100.0)$ & - & $974,831(88.42)$ \\
\hline Africa & - & - & $30,497(23.88)$ & $30,497(2.77)$ \\
\hline Asia & - & - & $4668(3.66)$ & $4668(0.42)$ \\
\hline Eastern Europe & - & - & $48,371(37.87)$ & $48,371(4.39)$ \\
\hline Latin America & - & - & $36,517(28.59)$ & $36,517(3.31)$ \\
\hline Western Europe \& North America & - & - & $7660(6.00)$ & $7660(0.69)$ \\
\hline \multicolumn{5}{|l|}{ Place of birth, $\mathrm{n}(\%)$} \\
\hline Spain & $956,444(100.0)$ & - & - & $956,444(86.75)$ \\
\hline Africa & - & $2647(14.40)$ & $30,579(23.94)$ & $33,226(3.01)$ \\
\hline Asia & - & $508(2.76)$ & $4684(3.67)$ & $5192(0.47)$ \\
\hline Eastern Europe & - & $257(1.40)$ & $48,360(37.87)$ & $48,617(4.41)$ \\
\hline Latin America & - & $10,059(54.71)$ & $36,883(28.88)$ & $46,942(4.26)$ \\
\hline Western Europe \& North America & - & $4916(26.74)$ & $7207(5.64)$ & $12,123(1.10)$ \\
\hline \multicolumn{5}{|l|}{ Length of stay in Spain, n (\%) } \\
\hline$<5$ years & - & $1922(10,45)$ & $77,323(60,54)$ & - \\
\hline$\geq 5$ years & - & $16,465(89,55)$ & $50,390(39,46)$ & - \\
\hline Length of stay in Spain, mean (SD) & - & $9,7(3,0)$ & $5,0(2,8)$ & - \\
\hline Deaths, n (\%) & $56,114(5.87)$ & $376(2.04)$ & $428(0.34)$ & $56,918(5.16)$ \\
\hline Deaths in women, $\mathrm{n}(\%)$ & $27,614(49.21)$ & $183(48.67)$ & $159(37.15)$ & $27,956(49.12)$ \\
\hline \multicolumn{5}{|l|}{ Deaths by age group, n (\%) } \\
\hline $15-44$ & $1027(1.83)$ & $24(6.38)$ & $147(34.35)$ & $1198(2.10)$ \\
\hline $45-64$ & $5855(10.43)$ & $94(25.0)$ & 169 (39.49) & $6118(10.75)$ \\
\hline $65+$ & 49,232 (87.74) & $258(68.62)$ & $112(26.17)$ & $49,602(87.15)$ \\
\hline Age at death, mean (SD) & $79.58(12.56)$ & $72.01(16.72)$ & $53.60(17.87)$ & $79.33(12.85)$ \\
\hline \multicolumn{5}{|l|}{ Deaths by nationality, n (\%) } \\
\hline Spain & $56,114(100.0)$ & $376(100.0)$ & - & $56,490(99.25)$ \\
\hline Africa & - & - & $76(17.76)$ & $76(0.13)$ \\
\hline Asia & - & - & $14(3.27)$ & $14(0.02)$ \\
\hline Eastern Europe & - & - & $165(38.55)$ & $165(0.29)$ \\
\hline Latin America & - & - & $84(19.63)$ & $84(0.15)$ \\
\hline Western Europe \& North America & - & - & 89 (20.79) & $89(0.16)$ \\
\hline \multicolumn{5}{|l|}{ Deaths by place of birth, $\mathrm{n}(\%)$} \\
\hline Spain & $56,114(100.0)$ & - & - & $56,114(98.59)$ \\
\hline Africa & - & $95(25.27)$ & $78(18.22)$ & $173(0.3)$ \\
\hline Asia & - & $14(3.72)$ & $14(3.27)$ & $28(0.05)$ \\
\hline Eastern Europe & - & $4(1.06)$ & $165(38.55)$ & $169(0.3)$ \\
\hline Latin America & - & $127(33.78)$ & $85(19.86)$ & $212(0.37)$ \\
\hline Western Europe \& North America & - & $136(36.17)$ & 86 (20.09) & $222(0.39)$ \\
\hline
\end{tabular}




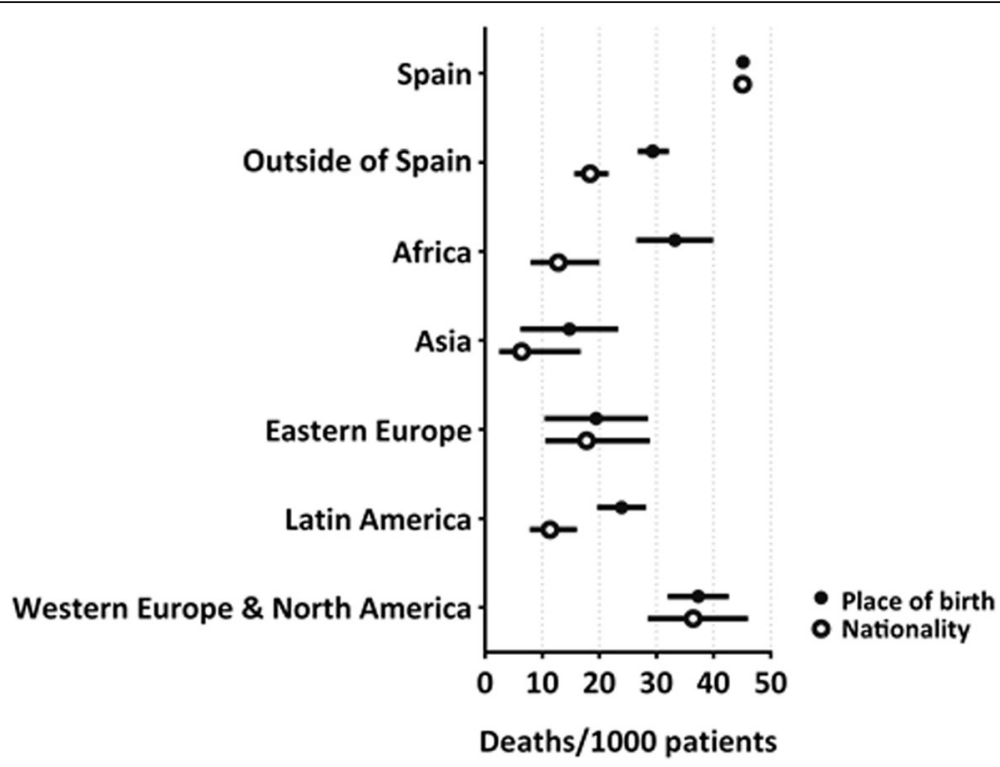

Fig. 1 Age- and sex-standardized number of deaths per 1000 subjects between years 2012-2015 according to place of birth and nationality

In general, the existence of a "healthy migration effect" is accepted as a justification for the better health outcomes seen in immigrant populations. However, some morbidity studies have highlighted the possibility of a registration bias during the first years of stay of immigrants. It is proposed that, even when ill, immigrants may not avail of healthcare services due to ignorance, work priorities, language problems, or other accessibility problems $[1,7,38]$. This hypothesis is not supported by our study, since the mortality registry in Spain is exhaustive and includes data even of individuals who do not avail of healthcare services. We cannot rule out the possible existence of "salmon bias", whereby sick migrants return to their countries of origin awaiting the outcome of disease. However, recent studies on mortality in immigrant populations have not supported this theory $[23,39]$.

Our results also show that mortality estimates in immigrants from Western Europe and North America are similar to those of the native Spanish population. While most immigrants from countries outside the European Union or North America come to Spain for economic reasons and end up working in unskilled jobs, those who emigrate from countries with a level of income equal to or greater than that of Spain probably

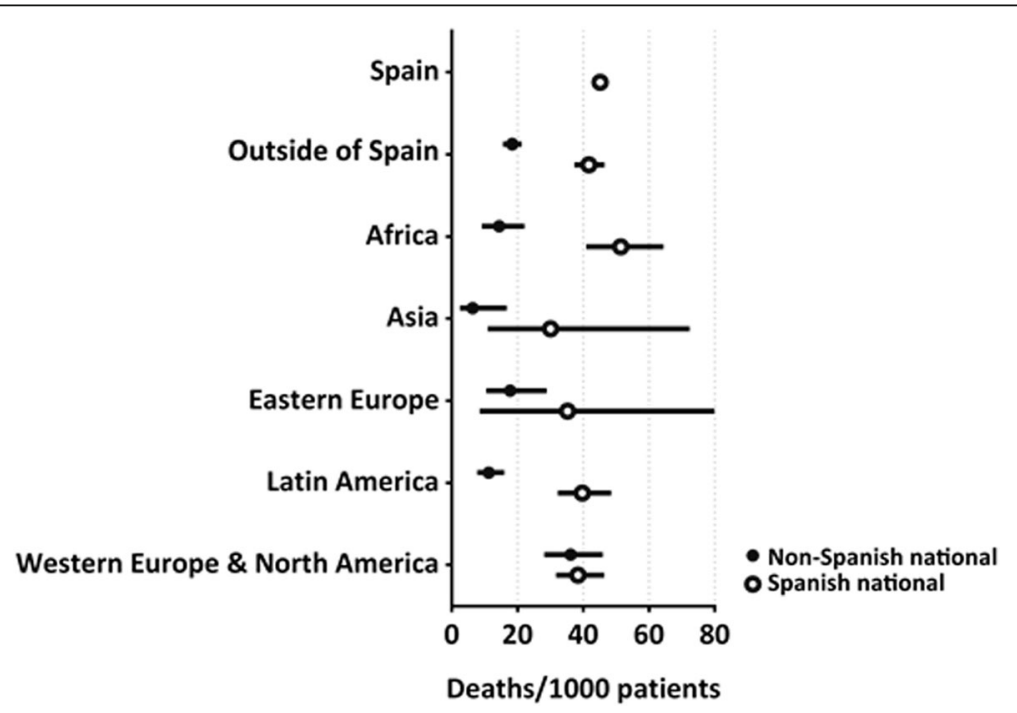

Fig. 2 Age- and sex-standardized number of deaths per 1000 subjects between years 2012-2015 by area of birth and according to nationality 


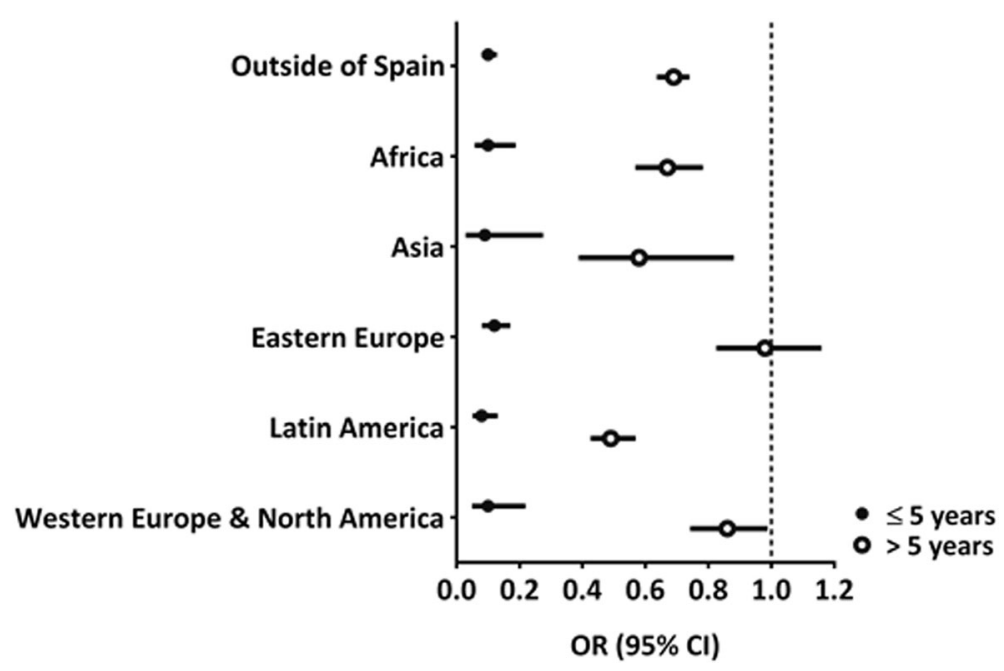

Fig. 3 Four-year probability of death in the foreign-born versus Spanish-born population according to length of stay, adjusted by age and sex

work in more skilled jobs, in which health status is less important [40]. However, in the absence of socioeconomic data we cannot confirm this hypothesis.

\section{Influence of length of stay}

The influence of length of stay in the host country on mortality has been less studied. Several studies conducted in Norway [16], Belgium [18], and Canada [15] have shown an increase in mortality with increasing length of stay. This finding has been related to the often poor socioeconomic conditions in which immigrants live $[6,17,34]$, the process of acculturation $[16,18,34]$, and allostatic overload [5, 38]. Our results suggest a clear temporal relationship, with length of stay in Spain constituting a "risk factor" for the health of immigrants. To some extent, immigrants "invest" their good health in improving the health of their families via the remittances they send to their countries of origin.

\section{Strengths and weaknesses}

The strengths of this study include region-wide coverage, the inclusion of all registered immigrants and the absence of selection bias, as well as the grouping of immigrants according to area of origin, which to a certain degree recognizes the heterogeneity of the immigrant population. The use of administrative data allowed us to study the effects of important sociodemographic characteristics such as region of origin and length of stay in the host country. The selection of the outcome variable "mortality" minimizes bias associated with registration problems, since the data corresponding to this variable are obtained from a database with broad coverage and good reliability.

Some limitations to the approach used should be noted. Our study did not consider socioeconomic variables such as income, education level, legal status, or reason for migration, which could have helped identify some of the complex factors that influence mortality.

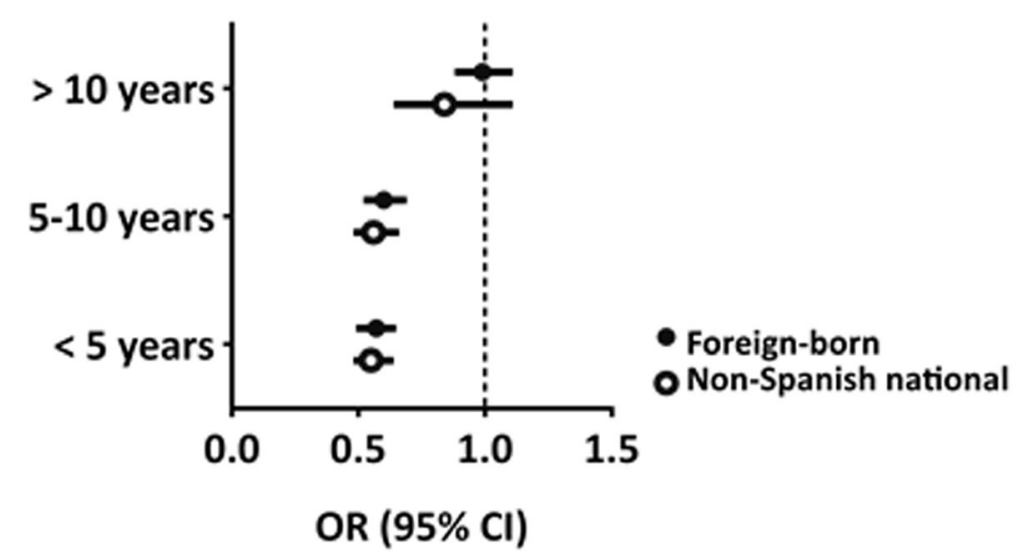

Fig. 4 Four-year probability of death in individuals born outside of Spain and in non-Spanish nationals with respect to individuals born in Spain, stratified according to length of stay and adjusted by age and sex 
This important personal information is not stored in Spanish healthcare databases and could not be obtained in any other way while preserving anonymity. Another weakness relates to our inability to take into account the "salmon bias" or "unhealthy remigration effect".

\section{Conclusions}

Defining immigrant status based on nationality instead of place of birth tends to result in different mortality estimates. Moreover, length of stay in the host country appears to be a key determinant of the health status of immigrants. This information should therefore be used to complement the aforementioned criteria when discriminating between the native population and non-nationals and/or foreign-born individuals. Overall, mortality estimates of immigrants are lower than those of the native population, although numbers tend to converge with increased length of stay of immigrants in the host country.

\section{Abbreviations \\ IOM: International Organization for Migration; n: Number; SD: Standard Deviation; USA: United States of America}

\section{Acknowledgements}

Not Applicable.

\section{Funding}

This study was supported by grant PI11/01126 from the Carlos III Health Institute of the Spanish Ministry of Economy and Competitiveness. This work was also co-supported by the EpiChron Research Group on Chronic Diseases B01_17R and co-funded by the Operational Program of the European Regional Development Fund (FEDER) Aragón 2014-2020: "Construyendo Europa desde Aragón". The funding sources had no role in the design of this study, its execution, analyses, interpretation of the data, in writing the manuscript or decision to submit results.

\section{Availability of data and materials}

The datasets used and analysed during the current study are available from the corresponding author upon reasonable request.

\section{Authors' contributions}

LAGF was the principal investigator who contributed to the conception and design of the study, interpreted the data, prepared the manuscript, led the paper and acted as corresponding author; CLB and BPP collected, analysed and interpreted the data; ACL, ED, CCS and APT participated in the conception and design of the study and helped to draft the paper. All authors read and approved the final manuscript.

\section{Ethics approval and consent to participate}

The study was approved by the Ethics Committee for Clinical Investigation of Aragón

\section{Consent for publication}

Not applicable.

\section{Competing interests}

The authors declare that they have no competing interests.

\section{Publisher's Note}

Springer Nature remains neutral with regard to jurisdictional claims in published maps and institutional affiliations.

\section{Author details}

${ }^{1}$ EpiChron Research Group on Chronic Diseases, Aragón Health Sciences Institute (IACS), IIS Aragón, Miguel Servet University Hospital, Zaragoza, Spain. ${ }^{2}$ Aragón Healthcare Service, San Pablo Health Centre, Zaragoza, Spain. ${ }^{3}$ Health Services Research on Chronic Patients Network (REDISSEC), Carlos III Health Institute, Madrid, Spain. ${ }^{4}$ Department of Medicine, Psychiatry and Dermatology, University of Zaragoza, Zaragoza, Spain. ${ }^{5}$ Department of Neurobiology, Care Sciences and Society, Aging Research Center, Karolinska Institutet, Stockholm, Sweden. ${ }^{6}$ Department of Global Public Health and Primary Care, Research Group for General Practice, University of Bergen, Bergen, Norway. ${ }^{7}$ Norwegian Centre for Minority Health Research, Oslo, Norway.

Received: 10 June 2018 Accepted: 15 February 2019

Published online: 28 February 2019

\section{References}

1. Rechel B, Mladovsky P, Ingleby D, Mackenbach JP, McKee M. Migration and health in an increasingly diverse Europe. Lancet. 2013;381(9873):1235-45.

2. International Organization for Migration., United Nations. World Migration Report 2018. In: IOM world migration report series. Geneva: International Organization for Migration : United Nations; 2017. p. 364.

3. Ikram UZ, Mackenbach JP, Harding S, Rey G, Bhopal RS, Regidor E, Rosato M Juel K, Stronks K, Kunst AE. All-cause and cause-specific mortality of different migrant populations in Europe. Eur J Epidemiol. 2016;31(7):655-65.

4. Hemminki K. Immigrant health, our health. Eur J Pub Health. 2014;24(Suppl 1):92-5.

5. Doamekpor LA, Dinwiddie GY. Allostatic load in foreign-born and US-born blacks: evidence from the 2001-2010 National Health and nutrition examination survey. Am J Public Health. 2015;105(3):591-7.

6. Castaneda H, Holmes SM, Madrigal DS, Young ME, Beyeler N, Quesada J. Immigration as a social determinant of health. Annu Rev Public Health. 2015;36:375-92.

7. Norredam M, Nielsen SS, Krasnik A. Migrants' utilization of somatic healthcare services in Europe--a systematic review. Eur J Pub Health. 2010; 20(5):555-63.

8. Gimeno-Feliu LA, Calderon-Larranaga A, Diaz E, Poblador-Plou B, MacipeCosta R, Prados-Torres A. Global healthcare use by immigrants in Spain according to morbidity burden, area of origin, and length of stay. BMC Public Health. 2016;16(1):450.

9. Diaz E, Ortiz-Barreda G, Ben-Shlomo Y, Holdsworth M, Salami B, Rammohan A, Chung RY, Padmadas SS, Krafft T. Interventions to improve immigrant health. A scoping review. Eur J Pub Health. 2017;27(3):433-9.

10. Perruchoud R, Redpath-Cross J. Glossary on migration. 2nd ed. Genova: IOM; 2011.

11. Urquia ML, Gagnon AJ. Glossary: migration and health. J Epidemiol Community Health. 2011;65(5):467-72.

12. Loue $\mathrm{S}$, Bunce $A$ : The assessment of immigration status in health research Vital and health statistics Series 2, Data evaluation and methods research 1999(127):1-115.

13. Garcia-Armesto S, Begona Abadia-Taira M, Duran A, Hernandez-Quevedo C, Bernal-Delgado E. Spain: health system review. Health Syst Transit. 2010; 12(4):1-295.

14. Prados-Torres A, Poblador-Plou B, Gimeno-Miguel A, Calderon-Larranaga A, Poncel-Falco A, Gimeno-Feliu LA, Gonzalez-Rubio F, Laguna-Berna C, MartaMoreno J, Clerencia-Sierra M, et al. Cohort profile: the epidemiology of chronic diseases and multimorbidity. The EpiChron cohort study. Int J Epidemiol. 2018;47(2):382-4f.

15. Omariba DW, Ng E, Vissandjee B. Differences between immigrants at various durations of residence and host population in all-cause mortality, Canada 1991-2006. Popul Stud. 2014;68(3):339-57.

16. Syse A, Strand BH, Naess O, Steingrímsdóttir ÓA, Kumar BN. Differences in all-cause mortality: a comparison between immigrants and the host population in Norway 1990-2012. Demogr Res. 2016;34(22):615-56.

17. Malmusi D, Borrell C, Benach J. Migration-related health inequalities: showing the complex interactions between gender, social class and place of origin. Soc Sci Med. 2010;71(9):1610-9.

18. Vandenheede H, Willaert D, De Grande H, Simoens S, Vanroelen C. Mortality in adult immigrants in the 2000s in Belgium: a test of the 'healthy-migrant' and the 'migration-as-rapid-health-transition' hypotheses. Tropical Med Int Health. 2015;20(12):1832-45. 
19. Stratton J, Mowat DL, Wilkins R, Tjepkema M. Income disparities in life expectancy in the City of Toronto and region of Peel, Ontario. Chronic Dis Inj Can. 2012;32(4):208-15.

20. Ng E. The healthy immigrant effect and mortality rates. Health Rep. 2011; 22(4):25-9.

21. Page A, Begg S, Taylor R, Lopez AD. Global comparative assessments of life expectancy: the impact of migration with reference to Australia. Bull World Health Organ. 2007:85(6):474-81.

22. Moncho J, Pereyra-Zamora P, Nolasco A, Tamayo-Fonseca N, Melchor I, Macia L. Trends and disparities in mortality among Spanish-born and foreign-born populations residing in Spain, 1999-2008. J Immigrant Minority Health. 2015;17(5):1374-84

23. Wallace M, Kulu H. Low immigrant mortality in England and Wales: a data artefact? Soc Sci Med. 2014;120:100-9.

24. Boulogne $R$, Jougla E, Breem Y, Kunst AE, Rey G. Mortality differences between the foreign-born and locally-born population in France (20042007). Soc Sci Med. 2012;74(8):1213-23.

25. Kibele E, Scholz R, Shkolnikov VM. Low migrant mortality in Germany for men aged 65 and older: fact or artifact? Eur J Epidemiol. 2008;23(6):389-93.

26. Razum O, Zeeb H, Akgun HS, Yilmaz S. Low overall mortality of Turkish residents in Germany persists and extends into a second generation: merely a healthy migrant effect? Trop Med Int Health. 1998:3(4):297-303.

27. Khlat M, Courbage Y. Mortality and causes of death of Moroccans in France, 1979-91. Popul. 1996:8:59-94.

28. Fedeli U, Ferroni E, Pigato M, Avossa F, Saugo M. Causes of mortality across different immigrant groups in northeastern Italy. PeerJ. 2015;3:e975.

29. Norredam M, Olsbjerg M, Petersen JH, Juel K, Krasnik A. Inequalities in mortality among refugees and immigrants compared to native Danes--a historical prospective cohort study. BMC Public Health. 2012;12:757.

30. Verropoulou G, Tsimbos C. Mortality by cause of death among immigrants and natives in a south European country: the case of Greece, 2011. J Immigr Minor Health Center for Minority Public Health. 2016;18(2):337-44.

31. Dupre ME, Gu D, Vaupel JW. Survival differences among native-born and foreign-born older adults in the United States. PLoS One. 2012;7(5):e37177.

32. Holmes JS, Driscoll AK, Heron M. Mortality among US-born and immigrant Hispanics in the US: effects of nativity, duration of residence, and age at immigration. Int J Public Health. 2015;60(5):609-17.

33. Singh GK, Hiatt RA. Trends and disparities in socioeconomic and behavioural characteristics, life expectancy, and cause-specific mortality of native-born and foreign-born populations in the United States, 1979-2003. Int J Epidemiol. 2006;35(4):903-19.

34. Singh GK, Miller BA. Health, life expectancy, and mortality patterns among immigrant populations in the United States. Can J Public Health. 2004;95(3): |14-21.

35. Elstad Jl, Overbye E, Dahl E. Prospective register-based study of the impact of immigration on educational inequalities in mortality in Norway. BMC Public Health. 2015;15:364.

36. Uitenbroek DG. Mortality trends among migrant groups living in Amsterdam. BMC Public Health. 2015;15:1187.

37. Tarnutzer S, Bopp M. Healthy migrants but unhealthy offspring? A retrospective cohort study among Italians in Switzerland. BMC Public Health. 2012;12:1104

38. Diaz E, Kumar BN, Gimeno-Feliu LA, Calderon-Larranaga A, Poblador-Pou B, Prados-Torres A. Multimorbidity among registered immigrants in Norway: the role of reason for migration and length of stay. Trop Med Int Health. 2015;20(12):1805-14

39. Norredam M, Hansen OH, Petersen JH, Kunst AE, Kristiansen M, Krasnik A, Agyemang C. Remigration of migrants with severe disease: myth or reality?--a register-based cohort study. Eur J Pub Health. 2015;25(1):84-9.

40. Giuntella O, Mazzonna F. Do immigrants improve the health of natives? J Health Econ. 2015:43:140-53.

\section{Ready to submit your research? Choose BMC and benefit from:}

- fast, convenient online submission

- thorough peer review by experienced researchers in your field

- rapid publication on acceptance

- support for research data, including large and complex data types

- gold Open Access which fosters wider collaboration and increased citations

- maximum visibility for your research: over $100 \mathrm{M}$ website views per year

At $\mathrm{BMC}$, research is always in progress.

Learn more biomedcentral.com/submissions 